IP Periodica Polytechnica Electrical Engineering and Computer Science

59(1), pp. 9-17, 2015

DOI: $10.3311 /$ PPee.7525

Creative Commons Attribution (1)

RESEARCH ARTICLE

\section{Mixed Integer Optimization of IDMT Overcurrent Relays in the Presence of Wind Energy Farms Using PSO Algorithm}

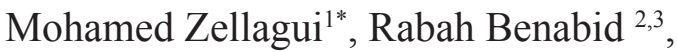 \\ Mohamed Boudour ${ }^{3}$, Abdelaziz Chaghi ${ }^{1}$ \\ Received 16 May 2014; accepted after revision 18 January 2015
}

\begin{abstract}
This paper presents an optimal coordination of inverse definite minimum time (IDMT) directional overcurrent relays (DOCR) in the presence of Wind Energy Farms (WEF). Firstly, the impact of WEF on the relays coordination is focused, after that we search for the new relays setting to ensure an optimal coordination of the relays. The coordination problem is formulated as a constrained nonlinear mono-objective optimization problem. The objective function of this optimization problem is the minimization of the operation time of the associated relays. In terms of decision variables; two types of optimizations are considered in this paper, namely: real parameter optimization where, the time dial setting (TDS), and the pickup current setting $\left(I_{P}\right)$ are considered as the real decision variables of the optimization problem and the mixed integer optimization, where the IEC curve characteristic of each relay is added to the previous variables as an integer decision variable. The characteristics of the relays are always chosen arbitrary or by trial and error method. To solve this constrained non linear optimization problem, the particle swarm optimization method is used. The proposed method is validated on IEEE 8-bus power transmission test systems considering various scenarios.
\end{abstract}

\section{Keywords}

Directional Overcurrent Protection, Fault Current, Wind Energy Farms, Optimal Coordination, Particle Swarm Optimization, Mixed Integer Constrained Optimization

\footnotetext{
${ }^{1}$ Department of Electrical Engineering, Faculty of Technology, University of Batna Campus CUB, 05000, Batna, Algeria

${ }^{2}$ Department of Electrical Engineering, Nuclear Center Research of Birine (CRNB), BP. 180, 17200, Djelfa, Algeria

${ }^{3}$ Department of Electrical Engineering, University of Sciences and Technology Houari Boumediene (USTHB), BP. 32, El Alia, Bab Ezzouar, 16111, Algiers, Algeria

*Corresponding author, e-mail: m.zellagui@univ-batna.dz
}

\section{Introduction}

With the continuous increase of power demand and the change of concerning environments, the capacities of renewable energy generation systems, which are mainly connected to a distribution system, are being expanded. The wind turbine generation (WTG) is a representative renewable energy system $[1,2]$. The process of high wind energy penetration requires the impact analysis of this new technology in power systems. In these terms, some countries have developed grid codes in order to establish the requirements of wind energy farms into power networks [2]. Moreover, power network planning with high wind energy penetration requires the definition of several factors, such as: the best technology to be used, the optimal number of units to be connected and the optimal size to be chosen. The wind energy industry is experiencing a strong growth in most countries in the last years. Several technical, economic and environmental benefits can be attained by connecting wind energy to distribution systems such as power loss reduction, the use of clean energy, postponement of system upgrades and increasing reliability. The doubly fed induction generator (DFIG) is currently the most commonly installed wind turbine in power systems [3]. However, due to the persistent enlargement of the power generation system including development of the WTG and its increased capacity, the level of associated short-circuit current during a fault will increase in the power system [4].

This increased short-circuit current can have a negative effect on the entire power grid including the WTG with respect to the protective coordination between directional overcurrent relays (DOCR). Since the coordination time interval (CTI) cannot be guaranteed if the fault current flowing through any protective device is changed, protective coordination will be lost and the unacceptable operation of protective devices may occur.

This may lead to a large damage in the system and decrease the system reliability. The DOCRs are usually placed at both ends of each line and their coordination is an important aspect in the protection system design. Relay coordination problem is to determine the sequence of relay operations for each possible fault location so that faulted section is isolated, with sufficient coordination margins, and without excessive time delays. This 
sequence selection is a function of power network topology relay characteristics and protection philosophy.

A number of technical papers have been published dealing with the impact of Distributed Generators (DG) on distribution network protection. Blinding of overcurrent relays is described in $[5,6]$, where the authors present the theoretical foundation of blinding, and in $[7,8]$, the authors present simulations results to demonstrate scenarios where the problem may occur. The concept of false tripping of a feeder presented in [5,9], the authors demonstrate the problem using examples and suggest the implementation of directional protection to overcome the problem. An increase and decrease in short circuit levels, undesirable network islanding and out of-synchronism reclose is investigated in [10]. However, when a fault occurs in a distribution network, it is important to quickly locate the fault by identifying either a faulty bus or a faulty line section in the network [11-12].

The optimal coordination of overcurrent relays in distribution systems with DG based on differential evolution algorithm (DEA) is presented in [13] and based on Discrete Differential Evolution Algorithm (D-DEA) in [14]. The application of Multi-Agent System (MAS) for protection coordination of radial systems in the presence of DG is presented in [15]. However the general impact of wind energy on overcurrent protection is presented in [16] and [17]. The impact of WTG equipped with DFIG on distance relay in the presence of three phase faults is highlighted in [18] and [19]. The WTG system sizing considering voltage regulation and DOCR coordination is pointed out in [20].

This paper presents the solution of the coordination problem of DOCR in the presence of wind energy farms with DFIG using PSO. The original PSO algorithm is enhanced in order to handle the constraint violation problem using penalty function. The problem is formulated as a non linear mixed integer constrained mono-objective optimization problem. The new ideas proposed in this paper are the impact of the WEF devices on the short-circuit current by taking into account the relay curve characteristic as a decision variable of the optimization problem. This characteristic is always chosen arbitrary or by trial and error method.

The remainder of this paper is presented as follows. Section 2 presents the impact of wind energy on power systems. Problem Formulation and Constraints of the optimal overcurrent relay coordination is presented in Section 3. The particle swarm optimization algorithm is presented in Section 4. Section 5 presents the case study and simulation results. The gained conclusions are presented in Section 6.

\section{Impact of Wind Energy on Power Systems}

Incorporation of great amount of distributed resources, such as wind energy, has a significant impact on power network, which are mainly related to environmental, economical and reliability aspects. Low wind penetration levels are usually accommodated in power networks considering that the network is passively controlled and operated.
Although there are several available tools to be used for wind power forecasting [21], wind energy is still considered as a non dispatchable and not centrally planned technology. Impact of wind energy on power systems is thus focused on several issues related to security, stability, power quality and operation of power systems [22].

- Wind energy has several impacts on power flow that could lead to reverse power flow and, as a result, power systems operation will become more complex.

- Moreover, power injection by wind farms may cause power losses in the distribution systems.

- All the utilities have to keep stable and reliable supply voltage to the customers within specific limits of frequency and magnitude. Connection of wind farms may result in voltage changes; consequently, some countries have defined a higher short circuit level at the connection point, normally between 20 and 25 times the wind farm capacity.

- Power quality is related to voltage variation and harmonic distortion in the network. However, the incorporation of wind energy in power networks could affect the quality of the supplied voltage to the customers. To reduce this impact, nowadays, variable speed wind turbines equipped with power electronics are widely used in wind energy conversion.

- Protection system is also affected by wind farms since the incorporation of wind power injection alters power flows; so that conventional protection systems might fail under fault situations.

- In the past, power network was passive operated and kept up stable under most circumstances. However, this statement is no longer valid if considering an increase of wind energy penetration. Recently, new requirements for wind units have been designed in order to keep power networks stable under several disturbances, such as low voltage ride through capability.

In spite of the positive impacts of DG on system design and operation [23], they change the original steady-state and fault current directions and values. The severity of these changes is based on the DG's location, capacity and number in distribution systems. As it is pointed out in [24], the fault contribution from a single small DG unit may not be large; however, the aggregate contributions of a few larger units, can alter the short-circuit levels enough to cause protective devices to malfunction.

A typical case is shown in Fig. 1. An industrial power network is fed through source $G$ and protected by $R_{1}, R_{2}$ and $R_{3}$. Each protective device is assigned a primary function to clear faults in a specific zone and a secondary function to clear faults in the adjacent or downstream zones to the extent within the range of the device permits. In this situation, the next upstream device, or device combination, must operate to provide backup 
protection. When two devices operate properly in this primary/ secondary mode for any system fault, they are said to be coordinated. Proper coordination is achieved by this discrimination between successive devices. Good practice dictates that when a fault $F_{1}$ occurs, the time of operation of relay $R_{2}$ should be made larger than the time of operation of $R_{1}$ at least by a time interval called the coordination time interval $(C T I)$. As clearly shown in Fig. $1, R_{2}$ will back up $R_{1}$.

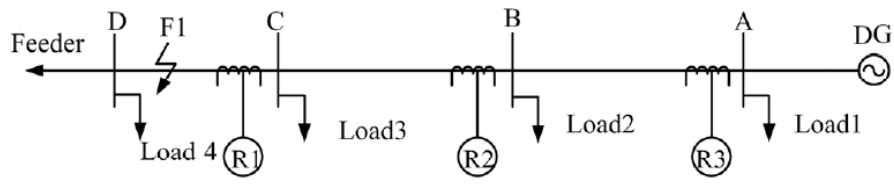

Fig. 1 Radial power system with DG.

It is clear that protection for distribution systems with DG (or WEF) cannot be achieved with the same philosophies that have been used to protect traditional distribution systems. At the very least, a system designed to protect distribution systems with DG should take the following into consideration. The other challenge is the variation of the short circuit current. On one hand, due to the change of the power system topology, such as losing some DGs and meshing the distributed feeder, the short circuit current would vary significantly. So the settings of the relays and the coordination of them should be adapted to the variation accordingly. However, the higher DG penetration makes it possible to operate the distribution system in an islanded mode, in which the distribution system works as a micro grid which is electrically isolated from the transmission system. When a distribution system is islanded, the fault current is lower than the fault current when the distribution system is connected to the transmission system [25].

\section{Problem Formulation and Constraints}

The coordination of the DOCR relays is formulated as a constrained optimization problem, where the optimization function and the constraints are presented as follows:

\subsection{Objective function}

The aim of this function is to minimize the total operating time of all DOCR relays in the system with respect to the coordination time constraint between the backup and primary relays.

$$
F=\operatorname{Min}\left\{\sum_{i=1}^{N R} t_{i}\right\}
$$

Where, $t_{i}$ represents the operating time of the relay $i, N R$ represents the number of relays in the power system. For each protective relay the operating time $t$ is defined as follows [27,28]:

$$
t(s)=\frac{\alpha \times T D S}{\left(\frac{I_{F}}{K_{C T} \times I_{P}}\right)^{\beta}-1}
$$

Where, $t$ is the relay operating time $(\mathrm{sec}), T D S$ is the time dial setting ( $\mathrm{sec}), I_{F}$ is the fault current $(A), I_{P}$ is the pickup current $(A), K_{C T}$ is the ratio of the current transformer. The constants $\alpha$ and $\beta$ depend on the characteristic curve for the IDMT directional overcurrent relay. Table 1 , defines the IEC relays characteristics.

Table 1. IEC relays characteristics

\begin{tabular}{ccc}
\hline & $\boldsymbol{\alpha}$ & $\boldsymbol{\beta}$ \\
\hline Normal inverse & 0.14 & 0.02 \\
\hline Very inverse & 13.5 & 1 \\
\hline Extremely inverse & 80 & 2 \\
\hline Long time inverse & 120 & 1 \\
\hline
\end{tabular}

\subsection{Optimization constraints}

\subsubsection{Coordination Time Interval (CTI)}

During the optimization procedure, the coordination between the primary and the backup relays must be verified. In this paper, the chronometric coordination between the primary and the backup relays is expressed by the following equation:

$$
t_{\text {backup }}-t_{\text {primary }} \geq C T I
$$

Where, $t_{\text {backup }}$ and $t_{\text {primary }}$ are the operating time of the backup and the primary relay respectively. $C T I$ is the minimum coordination time interval [29].

For the electromechanical relays, the $C T I$ value is varied between 0.30 to $0.50 \mathrm{sec}$, while for the numerical relays it is varied between 0.25 to $0.40 \mathrm{sec}$.

\subsubsection{Time dial setting (TDS) and pickup current setting $\left(I_{p}\right)$}

The TDS adjusts the time delay before the relay operates when the fault current reaches a value equal to, or greater than, the relay current setting $I_{P}$.

$$
\left\{\begin{array}{l}
T D S_{\min } \leq T D S \leq T D S_{\max } \\
I_{P \min } \leq I_{P} \leq I_{P \max }
\end{array}\right.
$$

Where, $T D S_{\min }$ and $T D S_{\max }$ are the minimum and the maximum limits of TDS respectively. $I_{P \min }$ and $I_{P \max }$ are the minimum and the maximum limits of current $I_{P}$ respectively. 


\subsection{Constraints violation handling}

During the optimization process, the coordination constraint presented in (3) could be violated. In this case, the penalty function presented in equation 5 is used to penalize the violated solutions.

$$
F_{1 \text { penalyzed }}=F_{1}+P F
$$

Where, $F_{1}$ is the objective function presented in (1) without penalization; and $\mathrm{PF}$ is the penalty function defined as follows:

$$
P F=\sum_{i=1}^{N R} \operatorname{Viol}(i)
$$

The Viol parameter is computed as follows:

- Set Viol [1:NR] =0

- For each pair of primary relay $i$ and backup relay $j$

- If, $t_{i}-t_{j} \geq C T I$

- $\operatorname{Viol}(i)=\operatorname{Viol}(i)+10$.

\section{Particle Swarm Optimization Algorithm}

The PSO is a population based stochastic optimization technique inspired by social behavior of bird flocking and fish schooling [30]. A PSO algorithm maintains a swarm of particles, where each represents a potential solution. In analogy with evolutionary computation paradigms, a swarm is similar to a population, while a particle is similar to an individual. Each particle adjusts its trajectory towards the best its previous position attained by any member of its neighborhood or globally, the whole swarm. The particles are flown through multidimensional search space, where the position of each particle adjusted according to its own experience and that of its neighbors.

The PSO method is based on a population of particles. Each particle in the swarm memorizes its current position in the research space, its velocity, its best position pbest, and the best position found by the swarm gbest. The displacement of each particle in the research space is based on its position and its velocity [31]:

$$
s_{i}^{k+1}=s_{i}^{k}+v_{i}^{k+1}
$$

Where, $s_{i}^{k+1}, s_{i}^{k}$ are the position of particle $i$ in the iteration $k+1$ and $k$, respectively. The velocity of each particle in the swarm is defined as follows:

$$
v_{i}^{k+1}=w v_{i}^{k}+c_{1} \text { rand }_{1} \times\left(\text { pbest }_{i}-s_{i}^{k}\right)+c_{2} \text { rand }_{2} \times\left(\text { gbest }-s_{i}^{k}\right)
$$

Where, $c_{1}$ and $c_{2}$ are the weighting factors, rand $_{1}$ and rand $_{2}$ are two uniform random numbers between zero and one. pbest $t_{i}$ is the best solution of the particle $i$, gbest is the best solution in the swarm, and $w$ is the weighting function defined as follows:

$$
w=w_{\max }-\frac{w_{\max }-w_{\max }}{\text { iter }_{\max }} \times \text { iter }
$$

Where, $w_{\max }$ and $w_{\text {min }}$ are the maximum and the minimum values of the weighting function. iter $_{\max }$ and iter are the maximum number of iteration and the current iteration respectively. The main steps of the PSO algorithm are presented as follows:

a) Initial population generation: in this step the population is generated randomly between limits. Each solution is considered as pbest and the best pbest is considered as gbest.

b) Objective function evaluation: the objective function value is computed for each particle. If the obtained solution is better that pbest. The pbest will take the value of the new solution. If the best value of the pbest is better than gbest, this last is substituted by this value.

c) Update of solution: the placement and velocity of each particle are updated using equations 7 and 8 respectively.

d) Check the stop criterion: if the maximal number of iteration is reached, the optimization is stopped and the optimal solutions are displayed.

\section{Case Study and Simulation Results}

As we mentioned above, the aim of this study is to highlight the impact of $W E F$ on relays coordination. To overcome any coordination problem due to the $W E F$, the $P S O$ technique is used in this paper.

Figure 2, presents the IEEE 8-bus test system. This system has two generators, with six buses, and seven transmission lines. The IEEE 8-bus system has a link to another network, modelled by a short circuit power of 400 MVA. Two WEF 1 and WEF 2 are connected to buses 4 and 5 respectively, where each WEF has four WTGs of 2.5 MVA. Therefore, the total power installed for each $W E F$ is $10 \mathrm{MVA}$.

The transmission network study consists of 14 numerical DOCRs relays. In this paper, the impact of WEF on DOCRs relays is studied considering several scenarios as follows:

- $\quad S C A$ : without $W E F$,

- $\quad S C B$ : with $W E F \mathrm{~s}$ :

- Case 1:WEF 1,

- Case 2:WEF 1 and WEF 2.

\subsection{Impact of WEF on fault current}

Figure 3 depicts the impact $W E F$ on the three phase fault current $\left(I_{F}\right)$ seen by the primary and backup overcurrent relays.

From Fig. 3, we can see that the installation of $W E F$ in power system has a great impact on the current fault, where, this last is increased with the installed $W E F$ power.

From these results we can conclude that the installation of WEF in power system has a great impact on the current fault and therefore on the coordination time interval (CTI) of the $P / B$ relays. 


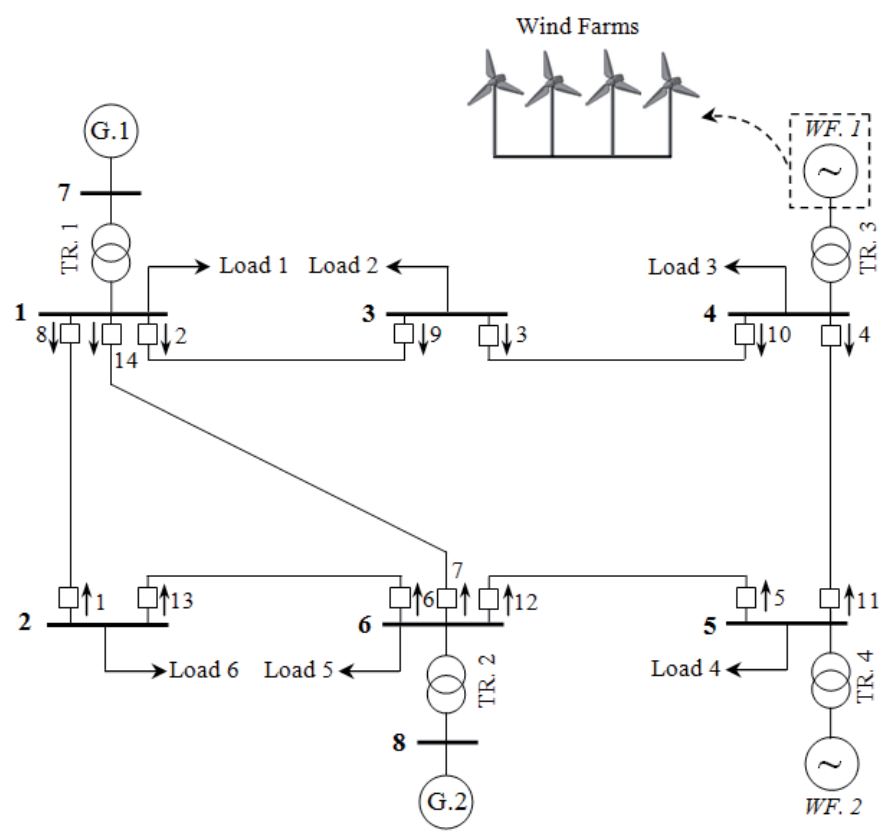

Fig. 2 WEFs connected to 8 bus transmission power system $150 \mathrm{kV}$.

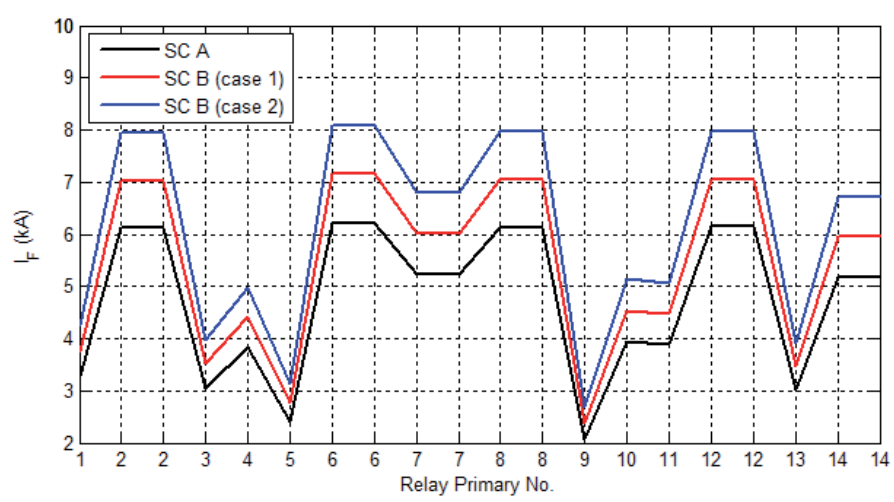

(a)



(b)

Fig. 3 Three phase fault current for all scenarios.

a). Primary relays, b). Backup relays.

\subsection{Impact of WEF on IDMT relays coordination}

Table 2 presents the optimal relays settings for the case without wind energy farms (SC A). These optimal settings are taken from [32].
Table 2 Optimal coordination solution without WEF (SC A) [32]

\begin{tabular}{|c|c|c|}
\hline \multirow{2}{*}{ IDMT Relay } & \multicolumn{2}{|c|}{ Control variables } \\
\hline & $T D S$ & $I_{P}$ \\
\hline 1 & 0.1000 & 1.6290 \\
\hline 2 & 0.1863 & 2.3730 \\
\hline 3 & 0.1845 & 2.0049 \\
\hline 4 & 0.1223 & 2.3452 \\
\hline 5 & 0.1000 & 1.6128 \\
\hline 6 & 0.1369 & 2.2587 \\
\hline 7 & 0.1777 & 2.2608 \\
\hline 8 & 0.1275 & 2.4413 \\
\hline 9 & 0.1000 & 2.3304 \\
\hline 10 & 0.1122 & 2.3713 \\
\hline 11 & 0.1356 & 2.1642 \\
\hline 12 & 0.1961 & 2.1354 \\
\hline 13 & 0.1000 & 1.6202 \\
\hline 14 & 0.1741 & 2.1989 \\
\hline
\end{tabular}

Table 3 presents, the CTI values with and without WEF. From this table, we can see that although the relays are well coordinated for $S C A$, however, most of them (CTI value written in bold) are not coordinated in the $S C B$ (case 1 and case 2).

This miss of coordination is mainly caused by the introduction of the $W E F$ in the power system.

From these results we can conclude that the installation of $W E F$ in the power system requires a new settings and coordination of the IDMT overcurrent relays.

\subsection{Optimal relays coordination in the presence of WEF using real parameter optimization}

In this case study, the PSO technique is used to overcome the relay coordination problem occurred in the presence of $W E F$. In this case, we have 28 real variables decision represented by the time dial setting $(T D S)$, and the pickup current setting $\left(I_{P}\right)$. The curve characteristic is not considered in the optimization process and it is fixed as IEC normal inverse.

The convergence characteristics of the PSO algorithm are presented in Fig. 4 and the new relays settings are presented in Table 4. The new coordination time of each $P / B$ relays are presented in Table 5.

From Table 5, we can remark that all $P / B$ relays are well coordinated expect Relays 5 and 4 are still not coordinated in the two cases of $S C B$. Therefore, we can conclude that with the normal inverse characteristic of the relays; the coordination can't be reached, and we propose to modify the relays characteristics. 
Table 3 Impact of wind farms on relay coordination time [32]

\begin{tabular}{|c|c|c|c|c|}
\hline \multirow{3}{*}{$\begin{array}{c}\text { Primary } \\
\text { Relay }\end{array}$} & \multirow{3}{*}{$\begin{array}{c}\text { Backup } \\
\text { Relay }\end{array}$} & \multicolumn{3}{|c|}{$C T I$ value (sec) } \\
\hline & & \multirow{2}{*}{ SCA } & \multicolumn{2}{|c|}{$S C B$} \\
\hline & & & Case 1 & Case 2 \\
\hline 1 & 6 & 0.2015 & 0.1833 & 0.1697 \\
\hline 2 & 1 & 0.2011 & 0.1353 & 0.0934 \\
\hline 2 & 7 & 0.2010 & 0.1733 & 0.1533 \\
\hline 3 & 2 & 0.2028 & 0.1767 & 0.1578 \\
\hline 4 & 3 & 0.2016 & 0.1889 & 0.1790 \\
\hline 5 & 4 & 0.2043 & 0.1798 & 0.1624 \\
\hline 6 & 5 & 0.3045 & 0.2411 & 0.1991 \\
\hline 6 & 14 & 0.3562 & 0.3179 & 0.2897 \\
\hline 7 & 5 & 0.2029 & 0.1484 & 0.1124 \\
\hline 7 & 13 & 0.4570 & 0.3382 & 0.2640 \\
\hline 8 & 7 & 0.3688 & 0.3314 & 0.3039 \\
\hline 8 & 9 & 0.2552 & 0.2054 & 0.1718 \\
\hline 9 & 10 & 0.2002 & 0.1713 & 0.1512 \\
\hline 10 & 11 & 0.2066 & 0.1830 & 0.1660 \\
\hline 11 & 12 & 0.2015 & 0.1885 & 0.1783 \\
\hline 12 & 13 & 0.2045 & 0.1362 & 0.0927 \\
\hline 12 & 14 & 0.2004 & 0.1702 & 0.1485 \\
\hline 13 & 8 & 0.2010 & 0.1800 & 0.1646 \\
\hline 14 & 1 & 0.4436 & 0.3308 & 0.2605 \\
\hline 14 & 9 & 0.2059 & 0.1528 & 0.1174 \\
\hline
\end{tabular}

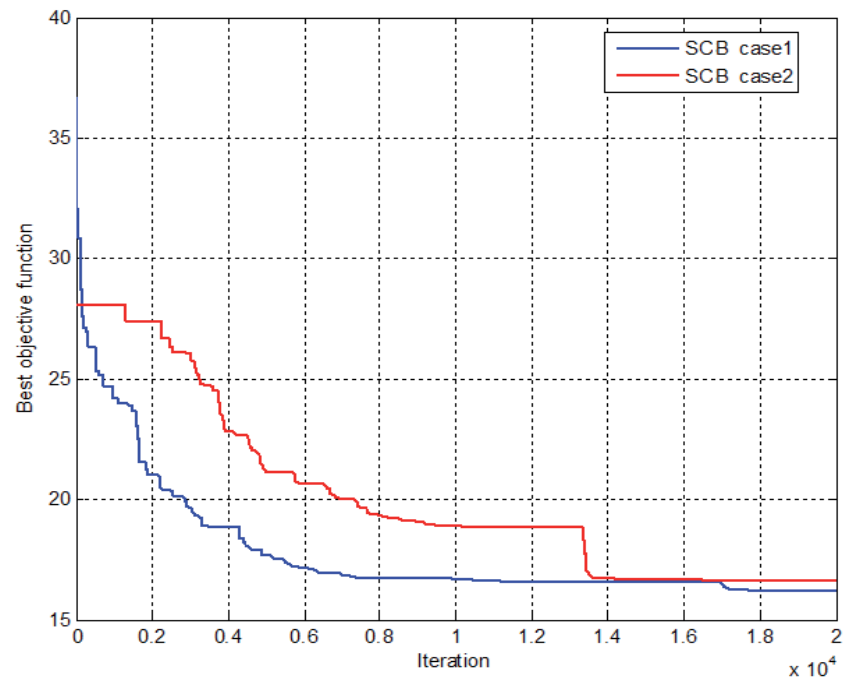

Fig. 4 PSO convergence characteristic of all optimization scenarios.
Table 4 Optimal coordination solution of $S C B$ (case 1 and case 2)

\begin{tabular}{|c|c|c|c|c|}
\hline \multirow{3}{*}{$\begin{array}{l}\text { IDMT } \\
\text { Relay }\end{array}$} & \multicolumn{4}{|c|}{ Control variables } \\
\hline & \multicolumn{2}{|c|}{$S C B$ (case 1) } & \multicolumn{2}{|c|}{$S C B$ (case 2) } \\
\hline & $T D S$ & $I_{P}$ & $T D S$ & $I_{P}$ \\
\hline 1 & 0.1000 & 2.5000 & 0.2504 & 0.5000 \\
\hline 2 & 0.2683 & 0.5000 & 0.1523 & 2.5000 \\
\hline 3 & 0.1071 & 2.5000 & 0.2050 & 0.5000 \\
\hline 4 & 0.1000 & 0.5000 & 0.1000 & 0.5000 \\
\hline 5 & 0.1000 & 2.5000 & 0.1000 & 2.5000 \\
\hline 6 & 0.2927 & 0.5000 & 0.1921 & 2.5000 \\
\hline 7 & 0.3140 & 0.5000 & 0.3095 & 0.5000 \\
\hline 8 & 0.1510 & 2.5000 & 0.1560 & 2.5000 \\
\hline 9 & 0.1187 & 2.5000 & 0.1404 & 2.5000 \\
\hline 10 & 0.1311 & 2.5000 & 0.3237 & 0.5000 \\
\hline 11 & 0.2994 & 0.5000 & 0.3775 & 0.5000 \\
\hline 12 & 0.4066 & 0.5000 & 0.2751 & 2.5000 \\
\hline 13 & 0.1000 & 2.5000 & 0.1013 & 2.5000 \\
\hline 14 & 0.2065 & 2.5000 & 0.2361 & 2.5000 \\
\hline
\end{tabular}

$\begin{array}{lll}\boldsymbol{F}(\mathbf{s e c}) & 16.2253 & 16.6420\end{array}$

Table 5 Coordination time of each $P / B$ pair of relays

\begin{tabular}{|c|c|c|c|}
\hline \multirow{2}{*}{$\begin{array}{c}\text { Primary } \\
\text { Relay }\end{array}$} & \multirow{2}{*}{$\begin{array}{c}\text { Backup } \\
\text { Relay }\end{array}$} & \multicolumn{2}{|c|}{$S C B$} \\
\hline & & Case 1 & Case 2 \\
\hline 1 & 6 & 0.2000 & 0.2000 \\
\hline 2 & 1 & 0.6246 & 0.3159 \\
\hline 2 & 7 & 0.2000 & 0.2081 \\
\hline 3 & 2 & 0.2000 & 0.2000 \\
\hline 4 & 3 & 0.2000 & 0.2000 \\
\hline 5 & 4 & -0.2344 & -0.2089 \\
\hline 6 & 5 & 0.4994 & 0.3311 \\
\hline 6 & 14 & 0.3899 & 0.4213 \\
\hline 7 & 5 & 0.4306 & 0.3224 \\
\hline 7 & 13 & 0.9984 & 0.7255 \\
\hline 8 & 7 & 0.2254 & 0.2000 \\
\hline 8 & 9 & 0.2807 & 0.3367 \\
\hline 9 & 10 & 0.2000 & 0.2000 \\
\hline 10 & 11 & 0.2000 & 0.2000 \\
\hline 11 & 12 & 0.2000 & 0.2039 \\
\hline 12 & 13 & 0.4191 & 0.2000 \\
\hline 12 & 14 & 0.2006 & 0.2000 \\
\hline 13 & 8 & 0.2000 & 0.2000 \\
\hline 14 & 1 & 0.8810 & 0.2000 \\
\hline 14 & 9 & 0.2000 & 0.2000 \\
\hline
\end{tabular}




\subsection{New formulation of the relays coordination problem in the presence of WEF using mixed integer optimization}

As can be seen in the previous section; the PSO is algorithm fails to find the relays coordination in the presence of $W E F$ considering predefined relay characteristic (i.e. normal inverse). In this section, we propose a new formulation of the relays coordination based on mixed integer optimization.

In this case, the optimization problem has 28 real variables decision represented by the time dial setting (TDS), and the pickup current setting $\left(I_{P}\right)$ and 14 integer variables decision represented by the relays characteristics (RelayType). The four relays characteristics presented in Table 1 are considered in the optimization process, and the coding of RelayType variable is presented in Table 6.

Table 6 Coding of the relay characteristic in the mixed integer optimization process

\begin{tabular}{cc}
\hline IEC Relay characteristic & Relay Type \\
\hline Normal inverse & 1 \\
\hline Very inverse & 2 \\
\hline Extremely inverse & 3 \\
\hline Long time inverse & 4 \\
\hline
\end{tabular}

During the optimization process, the variable RelayType is limited as follows:

$$
1 \leq \text { Relay Type } \leq 4
$$

The $P S O$ convergence characteristics for the mixed integer optimization of $S C B$ are presented in Fig. 5. Comparing figures 4 and 5, we can remark that the PSO takes less iterations number to converge in case of mixed integer optimization. The new optimal relays setting for $S C B$ case 1 and case 2 are presented in Tables 7 and 8. From these tables, we can see that, the objective function is well reduced compared with the real parameter optimization results.

Table 9 presents the $C T I$ values for both $S C B$ cases and shows that all $P / B$ relays are well coordinated. Therefore, the relays characteristic is an important parameter to ensure the relays coordination in the presence of $W E F$.

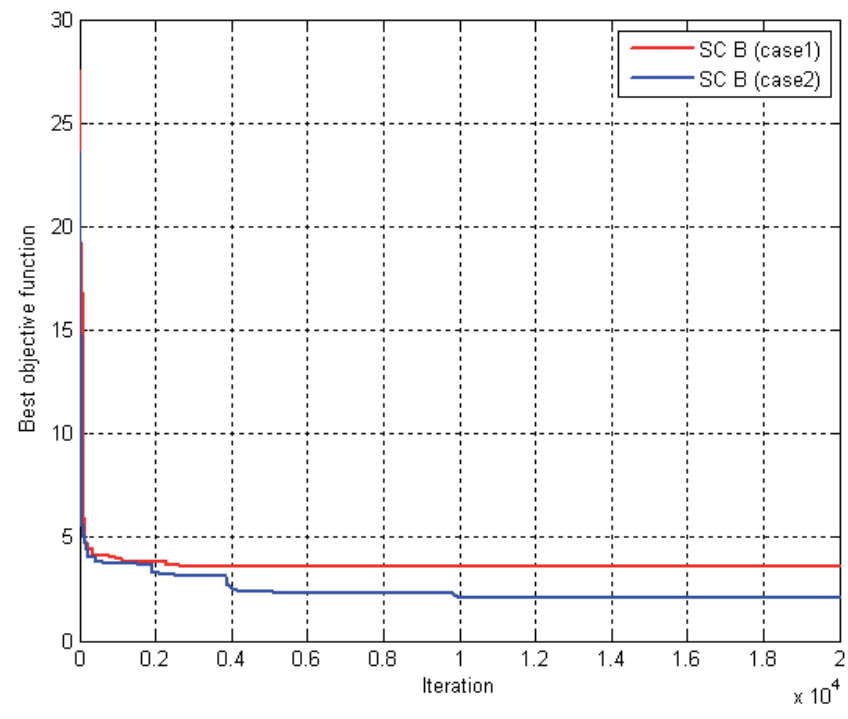

Fig. 5 PSO convergence characteristic of mixed integer optimization of $S C B$.

Table 7 Optimal relays coordination solution of $S C B$, case 1 .

\begin{tabular}{cccl}
\hline \multirow{2}{*}{ IDMT Relay } & \multicolumn{3}{c}{ Variables Control } \\
\cline { 2 - 4 } & $\boldsymbol{T D S}$ & $\boldsymbol{I}_{\boldsymbol{P}}$ & \multicolumn{1}{c}{ Relay Type } \\
\hline 1 & 0.1000 & 0.9997 & Extremely inverse \\
\hline 2 & 0.2784 & 2.5000 & Extremely inverse \\
\hline 3 & 0.1482 & 2.5000 & Normal inverse \\
\hline 4 & 0.1000 & 0.5000 & Long time inverse \\
\hline 5 & 0.1000 & 1.3981 & Extremely inverse \\
\hline 6 & 0.1000 & 0.5000 & Long time inverse \\
\hline 7 & 1.1000 & 2.5000 & Extremely inverse \\
\hline 8 & 1.1000 & 0.5000 & Very inverse \\
\hline 9 & 0.1000 & 2.5000 & Normal inverse \\
\hline 10 & 1.1000 & 0.5000 & Very inverse \\
\hline 11 & 0.1572 & 2.5000 & Extremely inverse \\
\hline 12 & 0.1301 & 0.5000 & Long time inverse \\
\hline 13 & 0.1000 & 2.5000 & Extremely inverse \\
\hline 14 & 1.1000 & 0.9324 & Extremely inverse \\
\hline $\boldsymbol{F}(\mathbf{s e c})$ & & 3.5626 & \\
\hline & & & \\
\hline
\end{tabular}


Table 8 Optimal relays coordination solution of $S C B$, case 2.

\begin{tabular}{|c|c|c|c|}
\hline \multirow{2}{*}{$\begin{array}{l}\text { IDMT } \\
\text { Relay }\end{array}$} & \multicolumn{3}{|c|}{ Variables Control } \\
\hline & $T D S$ & $I_{P}$ & Relay Type \\
\hline 1 & 0.1000 & 1.1389 & Extremely inverse \\
\hline 2 & 1.1000 & 1.3102 & Extremely inverse \\
\hline 3 & 0.2051 & 0.5000 & Normal inverse \\
\hline 4 & 1.1000 & 0.9410 & Extremely inverse \\
\hline 5 & 0.1000 & 0.9446 & Normal inverse \\
\hline 6 & 0.1000 & 0.5000 & Long time inverse \\
\hline 7 & 0.1569 & 2.5000 & Extremely inverse \\
\hline 8 & 1.1000 & 0.8413 & Extremely inverse \\
\hline 9 & 1.1000 & 0.6720 & Extremely inverse \\
\hline 10 & 0.1000 & 2.5000 & Extremely inverse \\
\hline 11 & 0.1046 & 2.5000 & Extremely inverse \\
\hline 12 & 0.2800 & 2.5000 & Extremely inverse \\
\hline 13 & 0.1000 & 1.0606 & Extremely inverse \\
\hline 14 & 1.1000 & 2.5000 & Extremely inverse \\
\hline$F(\sec )$ & & & \\
\hline
\end{tabular}

\section{Conclusions}

In this paper we present an optimal relays coordination in the presence of $W E F$. The obtained results show that the installation of $W E F$ in the power system has a great impact on the relay coordination. Therefore, we propose the formulation of the relays coordination problem as two constrained mono-objective optimization problems.

The first is a real parameter optimization that considers the $T D S$ and the $I_{p}$ of each relay as the real variables decision of the optimization problem. The second is a mixed integer optimization problem, where the relay type is coded as an integer variable decision which is added to the previous variables. To solve these complex optimization problems, the $P S O$ method is used for both real parameter and mixed integer optimizations.

The obtained results of the real parameter optimization show that the $P S O$ is fails to ensure the coordination of all $B / P$ relays. However, the mixed integer optimization shows a great capability to ensure the coordination of all $P / B$ directional overcurrent relays in the presence of $W E F$. Furthermore, the objective function is well reduced compared with the real parameter optimization.

The continuity of this work will be the coordination of the overcurrent relays in the presence of WEF and FACTS devices considering several conflicting objective functions and various power system topologies using multi-objective and hybrid optimization algorithms.
Table $9 C T I$ value of $S C B$ (case 1, and case 2)

\begin{tabular}{|c|c|c|c|}
\hline \multirow{3}{*}{$\begin{array}{c}\text { Primary } \\
\text { Relay }\end{array}$} & \multirow{3}{*}{ Backup Relay } & \multicolumn{2}{|c|}{$C T I$ value (sec) } \\
\hline & & \multicolumn{2}{|c|}{$S C B$} \\
\hline & & Case 1 & Case 2 \\
\hline 1 & 6 & 0.3639 & 0.3163 \\
\hline 2 & 1 & 0.2000 & 0.2314 \\
\hline 2 & 7 & 2.8880 & 0.2001 \\
\hline 3 & 2 & 0.2001 & 0.2000 \\
\hline 4 & 3 & 0.2000 & 0.2001 \\
\hline 5 & 4 & 0.4240 & 0.2000 \\
\hline 6 & 5 & 0.4509 & 0.2000 \\
\hline 6 & 14 & 0.2650 & 2.5296 \\
\hline 7 & 5 & 0.2000 & 0.3272 \\
\hline 7 & 13 & 4.7545 & 0.4232 \\
\hline 8 & 7 & 2.8265 & 0.2853 \\
\hline 8 & 9 & 0.3319 & 0.4208 \\
\hline 9 & 10 & 0.4058 & 0.2807 \\
\hline 10 & 11 & 0.1999 & 0.1999 \\
\hline 11 & 12 & 0.2000 & 0.2000 \\
\hline 12 & 13 & 2.8252 & 0.2000 \\
\hline 12 & 14 & 0.2000 & 2.5832 \\
\hline 13 & 8 & 0.2854 & 0.2000 \\
\hline 14 & 1 & 0.4481 & 0.2000 \\
\hline 14 & 9 & 0.5520 & 0.2000 \\
\hline
\end{tabular}

\section{References}

[1] Vittal, I., Ayyanar, R. "Grid Integration and Dynamic Impact of Wind Energy." Springer. UK. 2012.

[2] Ackermann, T. "Wind Power in Power Systems." $2^{\text {nd }}$ Edition, John Wiley \& Sons, Inc.. USA. 2012.

[3] Interconnection Agreements for Wind Energy and Other Alternative Technologies. Federal Energy Regulatory Commission.No. 661-A. USA. December. 2005.

[4] Ko, H. S., Yoon, G. G., Hong, W. P. "Active use DFIG-based VariableSpeed Wind-Turbine for Voltage Control in Power System Operation." Journal of Electrical Engineering \& Technology (JEET). 3 (2). pp. 254262. 2008

[5] Morren, J., De Haan, S. W. H. "Impact of Distributed Generation Units with Power Electronic Converters on Distribution Network Protection." in: 9th IET International Conference on Developments in Power System Protection (DPSP). Glasgow - UK, 17-20 March. 2008.

[6] Hussain, B., Sharkh, S. M., Hussain, S., Abusara, M. A. "Integration of Distributed Generation into the Grid - Protection Challenges and Solutions." in. 10th IET International Conference on Developments in Power System Protection (DPSP). Manchester - UK, 29 March-01 April. 2010.

[7] Baran, M., El-Markabi, I. "Adaptive Overcurrent Protection for Distribution Feeders with Distributed Generators." In. IEEE/PES Power Systems Conference and Exposition. New York - USA. 10-13 October. 2004. 
[8] Martinez, J. A., Martin-Arnedo, J. "Impact of Distributed Generation on Distribution Protection and Power Quality." in. IEEE Power and Energy Society General Meeting. Calgary - Canada. 26-30 July. 2009.

[9] Chaitusaney, S., Yokoyama, A. "Impact of Protection Coordination on Zizes of Several Distributed Generation Sources." In. 7th International Power Engineering Conference. Singapore. 29 November-02 December. 2005.

[10] Fazanehrafat, A., Javadian, S. A. M., Bathaee, S. M. T., Haghifam, M. R. "Maintaining The Recloser-Fuse Coordination in Distribution Systems in Presence of DG by Determining DG's Size." In. 9th IET International Conference on Developments in Power System Protection (DPSP). Glasgow - UK. 17-20 March. 2008.

[11] Zayandehroodi, H., Mohamed, A., Shareef H., Mohammadafari, M. "Automated Fault Location in a Power System with Distributed Generations Using Radial Basis Function Neural Networks." International Journal of Applied Sciences. 10 (3). pp. 3032-3041. 2010. DOI: $10.3923 /$ jas.2010.3032.3041

[12] Zayandehroodi, H., Mohamed, A., Shareef, H., Mohammadafari, M., "Performance Comparison of MLP and RBF Neural Networks for Fault Location in Distribution Networks with DGs." In. IEEE International Conference on Power and Energy (PECon). Kuala Lumpur - Malaysia. 29 November-01 December. 2010.

[13] Yang, H., Wen, F., Ledwich, G. "Optimal Coordination of Overcurrent Relays in Distribution Systems with Distributed Generators based on Differential Evolution Algorithm." European Transactions on Electrical Power (ETEP). 23 (1). pp. 1-12. 2013. DOI: 10.1002/etep.635

[14] Moirangthem, J., Krishnanand, K. R., Saranjit, N. "Optimal Coordination of Overcurrent Relay using an Enhanced Discrete Differential Evolution Algorithm in a Distribution System with DG." In. IEEE International Conference on Energy, Automation, and Signal (ICEAS). Odisha. 28-30 December. 2011.

[15] Maiola, P. C., Rolim, J. G. "A Multi-Agent System for Protection Coordination of Radial Systems in the Presence of Distributed Generation." In. 11th IET International Conference on Developments in Power System Protection. Birmingham - UK. 23-26 April. 2012.

[16] Comech, M. P., Montanes, M. A., Garcia, M. G. "Overcurrent Protection Behavior Before Wind Farm Contribution." In. 14th IEEE Mediterranean Electrotechnical Conference. Ajaccio - France. 5-7 May. 2008.

[17] Guo-Sheng, Y., Xin, L., Ze-Xin, Z. "The Impacts and Countermeasures of Distribution Relay Protection with Wind Power Connected." In. CIGRE/ IEEE PES Joint Symposium - Integration of Wide-Scale Renewable Resources into the Power Delivery System. Calgary - Canada. 29-31 July. 2009.

[18] De Rijcke, S., Pérez, P. S., Driesen, J. "Impact of Wind Turbines Equipped with Doubly-Fed Induction Generators on Distance Relaying. In. IEEE Power and Energy Society General Meeting. Minneapolis - USA. 25-29 July. 2010.

[19] Hansen, A. D., Michalke, G., Sorensen, P., Lund, T., Iov, F. "Coordinated Voltage Control of DFIG Wind Turbines in Uninterrupted Operation during Grid Faults." Wind Energy. 10 (1). pp. 51-68. 2007.

DOI: $10.1002 /$ we.207
[20] Hee-Jin, L., Gum-Tae, S., Jung-Wook, P. "Study on Wind-Turbine Generator System Sizing Considering Voltage Regulation and Overcurrent Relay Coordination." IEEE Transactions on Power Systems. 26 (3). pp. 1283-1293. 2011. DOI: 10.1109/TPWRS.2010.2091155

[21] González G. et al. "Wind Power Prediction Tool for the Spanish Peninsular Power System." In. Proceeding of the CIGRE. 40th General Session \& Exhibition. Paris - France. August. 2004.

[22] Alonso, M., Amarís, H. "Impact of Wind Farms in Power Systems." In. Wind Farm. InTech publishing. Croatia. 2011.

[23] Hadjsaid, N., Canard, J., Dumas, F. "Dispersed Generation Impact on Distribution Networks." IEEE Computer Applications in Power. 12 (2). pp. 22-28. 1999. DOI: 10.1109/67.755642

[24] Barker, P., De Mello, R. W. "Determining the Impact of DG on Power Systems - Radial Distribution." In. IEEE Power Engineering Society Summer Meeting. Seattle - USA. 16-20 July. 2000.

[25] Chengxi, L., Chen, Z., Zhou, L. "A Communication-Less Overcurrent Protection for Distribution System with Distributed Generation Integrated." In. 3rd IEEE International Symposium on Power Electronics for Distributed Generation Systems (PEDG). Aalborg - Denmark. 25-28 June. 2012.

[26] Müller, S., Deicke, M., De Doncker, R. W. "Doubly Fed Induction Generator Systems for Wind Turbines." IEEE Industry Applications Magazine. 8 (3). pp. 26-33. 2002. DOI: 10.1109/2943.999610

[27] Noghabi, A. S., Mashhadi, H. R., Sadeh, J. "Optimal Coordination of Directional Overcurrent Relays Considering Different Network Topologies using Interval Linear Programming." IEEE Transactions on Power Delivery. 25 (3). pp. 1348-1354. 2010. DOI: 10.1109/TPWRD.2010.2041560

[28] Chen, C. R., Lee, C. H., Chang, C. J. "Optimal overcurrent relay coordination in power distribution system using a new approach." International Journal of Electrical Power and Energy Systems. 45 (1). pp. 217-222. 2013. DOI: 10.1016/j.ijepes.2012.08.057

[29] Singh, M., Panigrahi, B. K., Abhyankar, A. R. "Optimal Coordination of Directional Overcurrent Relays using Teaching Learning-Based Optimization (TLBO) Algorithm." International Journal of Electrical Power and Energy Systems. 50. pp. 33-41. 2013. DOI: 10.1016/j.ijepes.2013.02.011

[30] Eberhart, R. C., Kennedy, J. "A New Optimizer using Particle Swarm Theory." in. 6th International Symposium on Micro Machine and Human Science (MHS). Nagoya - Japan. pp. 39-43. 1995.

[31] Malik, R. F., Rahman, T. A., Ngah, R., Mohd Hashim, S. Z. "New Particle Swarm Optimizer with Sigmoid Increasing Inertia Weight." International Journal of Computer Science and Security. 1 (2). pp. 35-44. 2007.

[32] Benabid, R., Zellagui, M., Chaghi, A., Boudour, M. "Optimal Coordination of IDMT Directional Overcurrent Relays in the Presence of Series Compensation using Differential Evolution Algorithm." In. 3th IEEE International Conference on Systems and Control (ICSC). Algiers Algeria. 29-31 October. 2013. 